
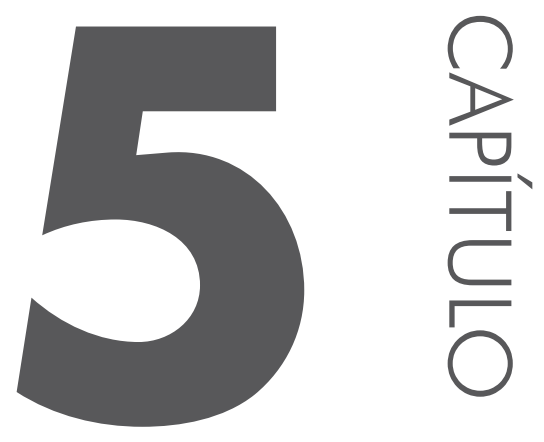

\title{
VARIÁVEL SEXO/GÊNERO E ALTERNÂNCIAS FONÉTICO- -FONOLÓGICAS EM FALARES DO RIO GRANDE DO SUL
}

\author{
Elisa Battisti \\ Claudia Camila Lara
}

\section{INTRODUC̣ÃO}

Estudos sociolinguísticos orientados pela Teoria da Variação (LABOV, 2008[1972]) vêm constatando que as mulheres lideram a aplicação de processos variáveis envolvendo variantes inovadoras não estigmatizadas (LABOV, 2001, 2010). Neste capítulo, retomamos os resultados de dois 
estudos que aparentemente contradizem essa tendência. Verificam que a liderança das mulheres pode não estar correlacionada ao prestígio das formas alternantes e que aos homens cabe algum protagonismo na aplicação de processos inovadores, o que se explica por padrões socioculturais locais.

A contribuição do trabalho está no fato de conciliar abordagem quantitativa e qualitativa de alternâncias fonético-fonológicas, indo do tratamento estatístico da variável sexo como categoria objetiva a gênero como identidade cultural e socialmente específica, para discutir a aparente contradição. Também presta contribuição ao tratar da aplicação de processos variáveis na fala de comunidades em que o contato portuguêslínguas de imigração ainda se verifica, o que colabora para a descrição do português brasileiro em variedades regionais matizadas pela fala bilíngue.

Os estudos retomados são de Lara (2013) e Battisti e Dornelles Filho (2015), que analisam, respectivamente, o vozeamento/desvozeamento variável de /p/ e /b/ (pudim [b]udim, bairro [p]airro) no português de contato com o Hunsrückisch, língua de imigração alemã falada no Brasil meridional; e a palatalização variável das plosivas alveolares diante de /i/ (tipo [t ] ] ipo, dica [d3]ica) no português de contato com a fala dialetal italiana na antiga região colonial do Rio Grande do Sul. As comunidades investigadas são Glória, situada na zona rural de Estrela, município gaúcho fundado em meados do século XIX por imigrantes alemães; e Flores da Cunha, município gaúcho fundado no final desse século por imigrantes italianos.

No estudo de Lara (2013), as mulheres lideram a aplicação do vozeamento/desvozemanto variável, mas a variante é estigmatizada. No estudo de Battisti e Dornelles Filho (2015), as mulheres aplicam mais o processo do que os homens, mas a análise mostra que as taxas de aplicação por mulheres têm se mantido estáveis nos últimos vinte anos, enquanto as dos homens sofreram grande incremento. As questões que daí surgem, e para as quais buscamos resposta, são: que elementos da sócio-história e cultura locais explicam os padrões de aplicação? De que quadro de práticas sociais de gênero localmente construído as variantes fazem parte?

Iniciamos o capítulo abordando os estudos de Lara (2013) e Battisti e Dornelles Filho (2015) em seu objeto, comunidade investigada e procedimentos metodológicos. Em seguida, passamos à apresentação e discussão dos resultados dos estudos, dando maior atenção ao verificado para sexo/gênero nas etapas quantitativa e qualitativa das análises. Nossas considerações finais fecham o capítulo. 


\subsection{OS ESTUDOS}

O vozeamento/desvozeamento variável de $/ \mathrm{p} / \mathrm{e} / \mathrm{b} /$ no português de contato com o Hunsrückisch, investigado por Lara (2013), caracteriza-se foneticamente por afetar o intervalo de tempo entre a soltura da plosiva e o início da vibração das cordas vocais. No vozeamento, a vibração das pregas vocais precede a soltura da consoante plosiva. No desvozeamento, a vibração das pregas vocais é simultânea, ou quase simultânea, à soltura da consoante plosiva.

De acordo com Altenhofen e Margotti (2011, p. 299), a realização variável das consoantes plosivas "explica-se pela inexistência, na língua materna (Hunsrückisch), da oposição desvozeada-vozeada, a qual leva à ausência de distinção em português”. Para os autores, o traço mais característico do português de contato com o adstrato alemão é o desvozeamento das obstruintes sonoras. É um dos mais estigmatizados socialmente e mais perceptível por um membro de outra comunidade de fala.

A palatalização, investigada por Battisti e Dornelles Filho (2015), afeta as consoantes /t/ e /d/ em seu ponto de articulação: são produzidas não com a obstrução à corrente de ar pelo toque da ponta da língua nos alvéolos, mas com o toque da língua um pouquinho mais para trás, em direção ao palato duro. Nessa posição, a língua antecipa o gesto articulatório necessário à produção de /i/, vogal seguinte que desencadeia o processo. $\mathrm{O}$ modo de articulação de /t/ e /d/ também é alterado: ocorre a africatização das consoantes, isto é, há um pequeno escape de ar ao final da articulação.

Conforme Noll (2008), a palatalização das plosivas alveolares é uma das mais marcantes características do português brasileiro no contraste com o português europeu. Ocorre na maior parte do Brasil, é um fenômeno urbano que possui, hoje, o status de padrão suprarregional. No Rio Grande do Sul, a proporção de palatalização em Porto Alegre é superior a 90\% (KAMIANECKY, 2002), mas inferior a 50\% em comunidades do interior do estado (BATTISTI, 2014).

A comunidade de fala abrangida por Lara (2013), Glória, situa-se na zona rural de Estrela, município do Vale do Rio Taquari. Caracteriza-se pelas atividades econômicas do setor primário (produção de leite, suíno, frango, milho, soja e mandioca). Glória possui cerca de 400 habitantes e Estrela, 32.535 (IBGE, 2014). O município de Flores da Cunha, comunidade de fala do estudo de Battisti e Dornelles Filho (2015), localiza-se no Nordeste do Rio Grande do Sul, na serra gaúcha. Seus principais setores econômicos são comércio, indústria (móveis, vinho), serviços e agricultura (uva, hortifrutigranjeiros). Sua população está em torno de 28.974 habi- 
tantes (IBGE, 2014).

\section{Figura 1: Localização dos municípios de Estrela e Flores da Cunha no Rio Grande do Sul.}
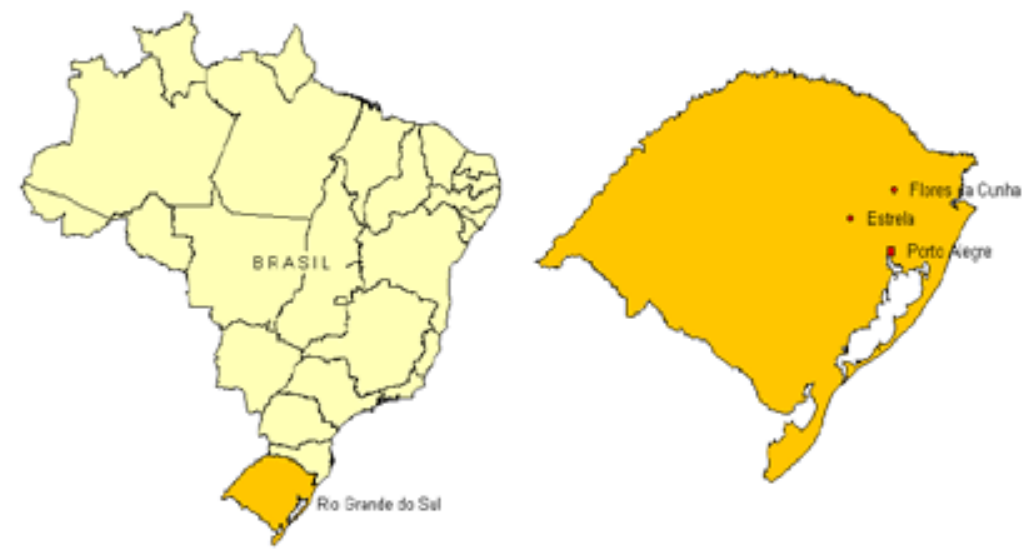

Tanto na comunidade de Glória quanto no município de Flores da Cunha, as atividades econômicas ligadas ao plantio e produção de alimentos são realizadas por núcleos familiares, em pequenas propriedades rurais. Sujeitos da geração mais nova não estão presentes nessas atividades. Deslocam-se à zona urbana para trabalhar no comércio, indústria e setor de serviços.

\subsubsection{Procedimentos de Lara (2013)}

Os dados de fala receberam tratamento sociolinguístico quantitativo, ou análise de regra variável (LABOV, 2008[1972]). Houve estudo qualitativo (MILROY, 1987) da rede social dos informantes e de suas práticas sociais em subgrupos da comunidade (comunidades de prática). Utilizou-se do método de análise de regra variável para a verificação dos fatores condicionadores (linguísticos e extralinguísticos) a que a variação das plosivas bilabiais /p, b/ encontra-se sujeita. Usou-se o pacote de programas VARBRUL, versão GoldVarb X, para verificar a tendência de o desvozeamento/vozeamento progredir, regredir ou manter-se estável na comunidade. A análise de rede social buscou examinar o papel do conhecimento mútuo e da intensidade do relacionamento dos entrevistados (MILROY, 1987, 2002) em grupos de sujeitos reunidos em torno de empreendimentos comuns (ECKERT, 2000) na difusão e manutenção das variantes.

Os dados para a análise de regra variável foram levantados de vinte e quatro entrevistas sociolinguísticas com habitantes de Glória. Nas entre- 
vistas, abordaram-se temas do cotidiano como a participação do indivíduo na comunidade, o convívio diário no local, a ocupação com as atividades profissionais e de lazer, as festividades relevantes para os moradores. A pesquisadora não utilizou a fala dialetal alemã, somente o português durante a entrevista. Mesmo assim, houve alguma alternância de código para o dialeto alemão na fala dos informantes, que conheciam a pesquisadora e sabiam de seu pertencimento à comunidade de Glória. Os informantes distribuíram-se em três faixas etárias (15 - 30 anos, 31 - 46 anos, 47 anos ou mais), três níveis de escolaridade (ensino fundamental, ensino médio e ensino superior) e dois sexos/gêneros (feminino e masculino). Posteriormente, elaborou-se a matriz de relacionamento em rede social dos informantes, que revelou comunidades de prática locais.

A análise quantitativa teve como variável dependente o vozeamento de $/ \mathrm{p} /$ e desvozeamento de /b/. As variáveis independentes, linguísticas e sociais, foram: contexto precedente, contexto seguinte, sonoridade da consoante-alvo, tonicidade da sílaba, número de sílabas, sexo/gênero, idade, escolaridade, bilinguismo.

$\mathrm{Na}$ realização das entrevistas sociolinguísticas, obtiveram-se também informações para a análise de rede social, conforme uma matriz de relacionamentos em rede. A partir dos estudos de Blake e Josey (2003), usou-se uma escala de três graus de relacionamento para elaborar essa matriz de rede conforme a cultura local: um para o convívio diário, dois para a frequência de encontro semanal (regular) ou mensal (eventual) e o valor mínimo de conectividade, três, para pouca frequência, ou seja, encontro anual (raro) ou para os informantes sem vínculo atual.

$\mathrm{Na}$ última etapa, analisou-se a participação dos sujeitos nas atividades de comunidades de prática reveladas na análise de rede social: Clube de Mães, Coral, Teatro e Igreja. Durante o ano de 2012, a pesquisadora observou as práticas sociais nessas comunidades, buscando averiguar o engajamento dos sujeitos e o valor das variantes nesses grupos.

\subsubsection{Procedimentos de Battisti e Dornelles Filho (2015)}

A etapa quantitativa do estudo consistiu numa análise em tempo real, estudo de tendência (LABOV, 1994): um tempo depois e na mesma comunidade de fala, analisam-se dados de fala do mesmo número de entrevistas, de informantes de mesmo perfil, mas não exatamente os mesmos informantes. Para tanto, utilizaram-se doze entrevistas sociolinguísticas de informantes de Flores da Cunha do VARSUL (UFRGS, UFSC, UFPR, PUCRS) realizadas em 1990 e doze do BDSer (UCS) realizadas de 2008 a 2009 no mesmo município. Como a estratificação etária é diferente nesses 
dois bancos de dados - os informantes do VARSUL distribuem-se em dois grupos etários, os do BDSer, em quatro - consultou-se a ficha social dos informantes e, com base na idade declarada no momento das entrevistas, conseguiu-se chegar a três grupos etários (25 a 39 anos, 40 a 59 anos, 60 ou mais anos) compatíveis nos dois bancos. Além disso, distribuíram-se os informantes por sexo/gênero (masculino e feminino).

Os dados levantados das vinte e quatro entrevistas foram codificados conforme as seguintes variáveis: (a) Dependente: palatalização de /t $\mathrm{d} /$ desencadeada por vogal anterior alta subjacente /i/ (tia [t]]ia, dia [d3] ia) ${ }^{1}$; (b) Independentes - sociais: idade $(25-39,40-59,60$ ou mais anos) e sexo/gênero (feminino, masculino); independentes - linguísticas: contexto fonológico precedente, contexto fonológico seguinte, status da vogal alta, qualidade da consoante-alvo, posição da sílaba na palavra, tonicidade. Os dados codificados foram então submetidos ao pacote de programas VARBRUL, versão Goldvarb X, para análise de regra variável (LABOV, 2008 [1972]), com que se buscou verificar se, no intervalo de vinte anos, a palatalização teria progredido na comunidade, se a tendência à progressão da regra ainda se mantém, como também as variáveis condicionadoras do processo.

A etapa qualitativa do estudo, na linha de Eckert (2000), envolveu análise de conteúdo das entrevistas sociolinguísticas e de matérias de jornal local, com que se verificou que as práticas sociais afirmadas pelos informantes e aquelas que mereceram cobertura jornalística pertencem sobretudo às categorias Família, Trabalho, Religião, Estudo, Lazer. Houve observação de práticas sociais em Flores da Cunha de 2008 a 2013, tanto na ida à comunidade para a realização das entrevistas, quanto em visitas a festas e celebrações locais - Corpus Christi, Fenavindima, Festa Colonial da Uva.

1 Diferentemente de Battisti e Rosa (2012), Battisti e Dornelles Filho (2015) incluíram na análise apenas dados com /e/ após /t,d/ em sílaba átona em que houve a efetiva elevação da vogal. A elevação de /e/ em sílaba átona, regra que alimenta a palatalização no português brasileiro, é pouco expressiva em Flores da Cunha. Além disso, de acordo com Battisti e Rosa (2012, p. 20), metade das vogais [i] derivadas de /e/ não desencadeia a palatalização: nos dados do VARSUL, a elevação foi de $25 \%$ e a palatalização de /t d/ por [i] elevado de /e/ foi de $11 \%$. Nos dados do BDSer, a elevação foi de $32 \%$ e a palatalização de /t d/ por [i] elevado de /e/ foi de $15 \%$. 


\subsection{RESULTADOS}

\subsubsection{Lara (2013)}

$\mathrm{Na}$ análise quantitativa de 14189 contextos de vozeamento/desvozeamento das plosivas bilabiais, obteve-se a proporção total de aplicação de apenas $1,6 \%$. A tendência geral de aplicação da regra, expressa pelo input 0,003, é muito baixa. Isso sugere que a realização analisada seja residual, venha a desaparecer da fala em português brasileiro (doravante PB) num futuro relativamente próximo.

Mesmo sendo baixa a aplicação, o processo apresenta alguma sistematicidade. A análise revelou que as variáveis sonoridade da consoante-alvo, escolaridade, contexto precedente, bilinguismo, sexo/gênero e tonicidade da sílaba têm papel no vozeamento/desvozeamento das plosivas. Do ponto de vista social, o sexo/gênero feminino, falantes com mais de 47 anos, com nível fundamental e médio de escolaridade e bilíngues ativos condicionam a aplicação da regra. Do ponto de vista linguístico, a consoante-alvo /b/, o tepe precedente, a sílaba tônica condicionam o processo.

O papel do sexo/gênero feminino na aplicação do vozeamento/desvozeamento das plosivas fica um pouco mais claro no cruzamento de grupos de fatores, como o das variáveis sexo/gênero e idade. O resultado desse cruzamento apresenta-se na Figura 2:

Figura 2: Cruzamento de sexo/gênero e idade

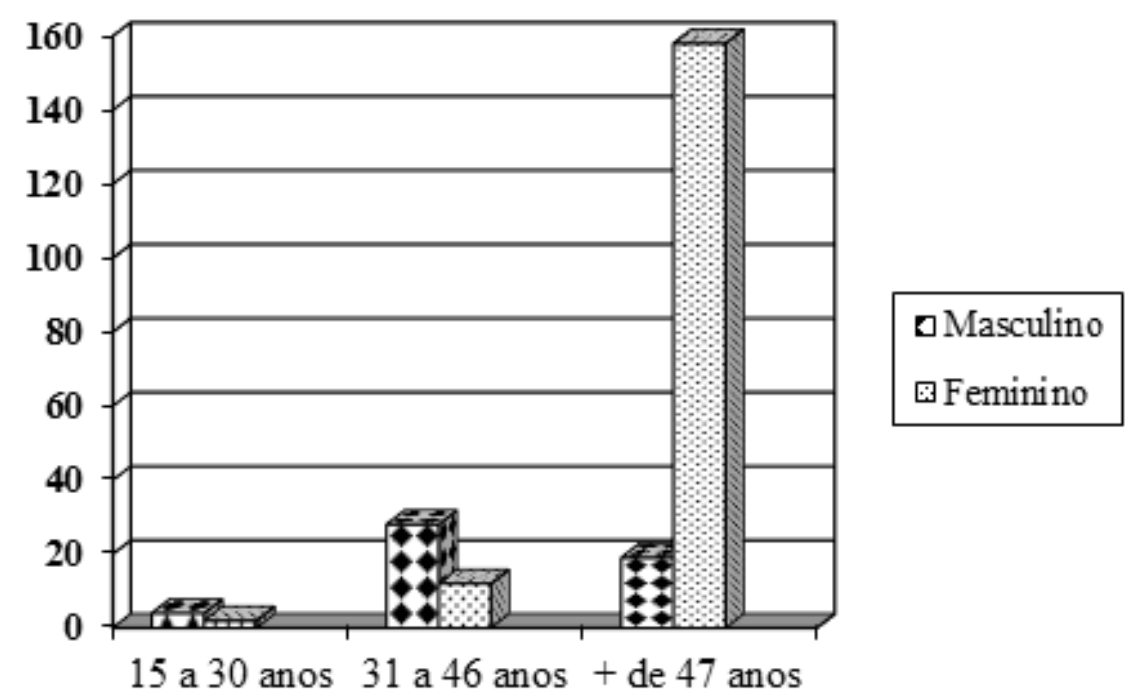


O cruzamento mostra que, nos grupos etários mais jovens, o sexo/gênero masculino apresenta uma proporção de aplicação da regra levemente maior do que a do sexo/gênero feminino. É no grupo etário mais velho que esse comportamento se inverte: a proporção de aplicação do sexo/gênero feminino é bastante maior do que a do sexo/gênero masculino. Talvez o fato de os homens mais velhos (+ de 47 anos) terem tido a oportunidade de seguir seus estudos em centros urbanos quando jovens, e as mulheres não, justifique esse comportamento. Por isso, realizou-se o cruzamento de sexo/ gênero e escolaridade. Os resultados estão na Figura 3:

\section{Figura 3: Cruzamento de sexo/gênero e escolaridade.}

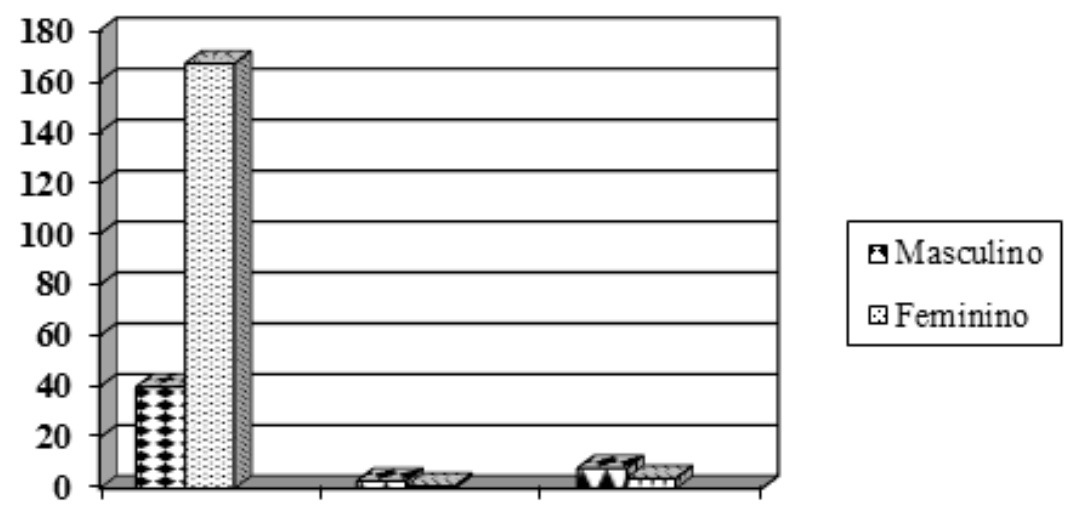

Ens. fund. Ens. méd. Ens. sup.

Apenas no nível fundamental de escolaridade há diferenças sensíveis entre os sexos/gêneros na aplicação da regra, em que se destaca o sexo/ gênero feminino. Nos outros níveis, o contraste entre os sexos/gêneros é quase inexistente. Isso sustenta a ideia de que, se o sexo/gênero feminino e não o masculino, como se esperava, promove a regra, tal papel se relacione com menores índices de escolaridade. Mais elucidativo é o cruzamento das variáveis idade e escolaridade, cujos resultados estão na Figura 4: 
Figura 4: Cruzamento de idade e escolaridade.

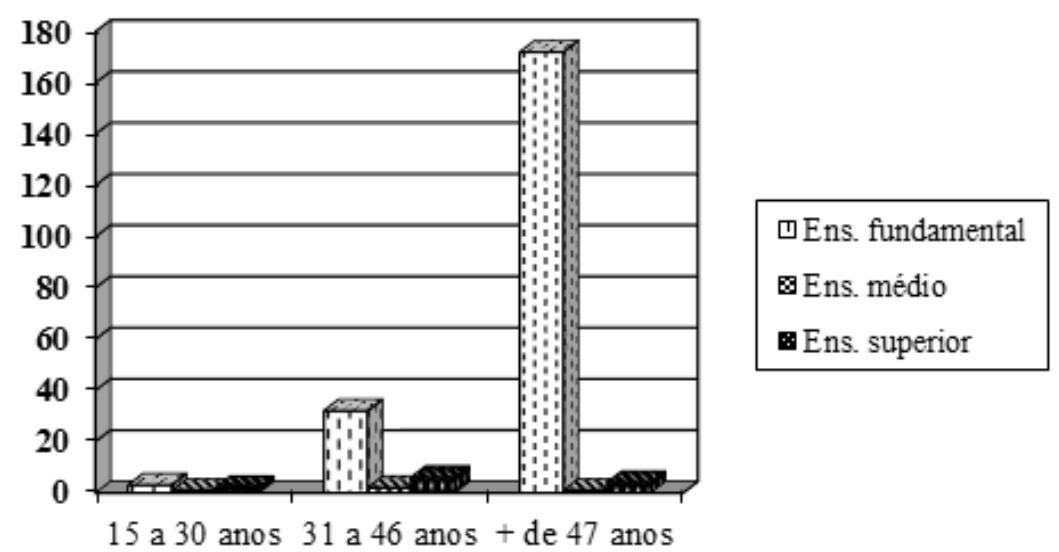

No grupo etário mais jovem, a diferença entre os níveis de escolaridade é irrelevante. À medida que a idade aumenta, o nível fundamental de escolaridade passa a ter papel na aplicação da regra. Reforça-se a ideia de que, quanto maior a escolaridade, o contato com o PB e a realização de práticas sociais em $\mathrm{PB}$, menor é a incidência da realização do processo variável. A escolarização hoje no Brasil é mais efetiva do que foi há $30 \mathrm{ou}$ 40 anos, quando menos pessoas cursavam ensino universitário e os níveis de escolarização nas comunidades rurais eram muito baixos.

Os resultados da análise de regra variável e os cruzamentos auxiliaram a compreender tanto a baixa aplicação da regra de vozeamento/desvozeamento das plosivas bilabiais quanto as variáveis a que se correlaciona essa característica residual do contato $\mathrm{PB}-$ Hunsrückisch no português falado em Glória. A análise de rede social, com consideração às comunidades de prática em que as redes se consolidam, auxiliou a esclarecer, em um nível mais próximo ao dos indivíduos, o que a análise de regra variável constatou.

A análise de rede social, de acordo com Milroy (1987), indica o quanto uma pessoa influencia ou é influenciada por seus contatos nas comunidades de que faz parte.

A matriz de relacionamento em rede dos informantes de Glória representa uma rede de alta densidade e multiplexa: todos os informantes se conhecem, sabem uns dos outros e se localizam dentro da comunidade. Ou, ainda, já participaram de atividades em comum, mas no momento não interagem mais. A maioria dos indivíduos conecta-se múltiplas vezes, por participarem de mais de uma comunidade de prática ou serem familiares 
íntimos. Um exemplo disso são os informantes A.S. e C.S., que participam das comunidades de prática coral e igreja e são casados; ou os informantes G.S e A.C., que são vizinhos e participam do grupo de teatro.

Verificou-se, durante as entrevistas sociolinguísticas e nas interações nas comunidades de prática, que os informantes, ao interagirem, praticam o bilinguismo de forma alternada: ora falam PB, ora Hunsrückisch. Por exemplo, isso ocorreu em uma situação em que um membro, feminino, com mais de 47 anos, participante do coral chegou para o ensaio e cumprimentou os demais falando Hunsrückisch. Observou-se que muitos responderam o cumprimento no dialeto, mas os mais jovens cumprimentaram em $\mathrm{PB}$ e, imediatamente, o membro que acabara de chegar os cumprimentou em PB.

As práticas bilíngues realizadas pelos membros do coral ocorrem nos ensaios, nas reuniões, em ocasiões informais, mas restringem-se à interação de indivíduos bilíngues ativos e passivos. Nas ocasiões em que se apresentam, na missa ou em bailes, os coralistas manifestam-se em PB. O Hunsrückisch aparece apenas nos cantos. Isso denota que o veículo de comunicação hoje é o PB. O falar Hunsrückisch tem valor, é um elemento da memória local, que se faz presente em festividades coletivas, porém não é mais prática social diária, com que se constituem as identidades na comunidade, em grupos de que os habitantes de Glória fazem parte, como o coral. Os informantes não parecem ter vergonha ou menosprezar abertamente o falar dialetal alemão. Ele apenas vem perdendo força porque os indivíduos não fazem mais uso dele nas interações realizadas em seu cotidiano, na vida em sociedade. É o que se percebe até mesmo nas atividades realizadas pelo coral. Delas participam bilíngues ativos e passivos, mas o PB predomina na maior parte das interações.

No que se refere especificamente ao efeito do sexo/gênero feminino no vozeamento/desvozeamento das plosivas bilabiais, a observação de práticas sociais em subcomunidades de Glória foi reveladora dos papéis desempenhados pelas mulheres e sua relação com o processo investigado. Ser mulher em Glória é comportar-se como gente grande (adulta) desde a infância. As mulheres são orientadas para o trabalho, ajudam em casa ou na escola. As mais novas (15 a 30 anos) aprendem com suas mães e avós (mais de 47 anos) a trabalhar, cuidar da casa e dos filhos e a participar das atividades da comunidade. Aquelas que se deslocam para as cidades (Estrela, Fazenda Vilanova, Bom Retiro do Sul, Teutônia, Lajeado e outras) para trabalhar durante o dia no comércio, escritórios, bancos, supermercados e nas indústrias geralmente estudam no turno da noite. Cursam o ensino médio ou graduação. Desenvolvem atividades não-locais, ou seja, deslocam-se para outros lugares em função de atividades profissionais. Esse é o maior grupo 
atualmente. Nessa faixa etária, se encontram também algumas mulheres trabalhando em casa e na comunidade em atividades agrícolas como o plantio de milho, soja e outros produtos; no trato de vacas leiteiras, suínos e aves (frango de corte). É o que fazem as informantes T.L., de 26 anos e D.A., 17 anos, que se dedicam, por opção, à agricultura. Sobre o deslocamento diário à zona urbana e estudo à noite, veja-se, para ilustração, um trecho de entrevista sociolinguística:

...trabalho de dia numa instituição financeira, volto pra casa, tomo meu banho, vô pra escola, quando volto, às vezes, tem trabalho pra fazê [...], há oito anos fazendo a faculdade. [...] eu tenho colegas inclusive que foram meus colegas de aula que hoje tão seguindo a atividade junto com os pais, né, muita área de terra, uns com leite, uns com suínos, aves, conheço bastante gente. [...] eu quando chego em casa [...] tô na rua, né, tô mexendo no pátio, alguma coisa a gente sempre faz. (G.S., fem., 28 anos)

As mulheres da faixa etária intermediária (31 a 46 anos) trabalham fora, isto é, nos centros urbanos, ou nas propriedades rurais familiares, em casa. Nesse grupo, observa-se uma mudança em relação às mulheres do grupo mais velho (mais de 47 anos): passaram a acompanhar os homens nos negócios, por exemplo. As informantes M.K, 45 anos e A.S., 39 anos, começaram a fazer faxina na cidade (como diaristas), a trabalhar em fábricas, além de participar ativamente na administração das propriedades rurais juntamente com os maridos. A respeito de atividades diárias dessa faixa etária, veja-se outro trecho de entrevista sociolinguística:

Meu dia a dia é levantá cedo, botá o café na mesa, se arrumá e vô pro serviço, eu trabalho o dia inteiro fora, volto de tardezinha, né. [...] a gente sai assim quando tem alguma coisa, a gente participa da comunidade e assim quando tem algum evento (festas da comunidade) a gente sempre, sempre ajuda, né, não tem um evento que a gente fica de fora, a gente sempre trabalha ou participa da diretoria (da comunidade). [...] eu assumi a sê candidata a presidente do coral, né, eu escolhi então doze mulheres, né, a diretoria é formada só por mulheres. (A.S., fem., 42 anos)

No grupo etário mais velho (mais de 47 anos), estão mulheres ainda na ativa e mulheres já aposentadas. A rotina das mulheres trabalhadoras nesse grupo etário não é muito diferente da rotina no grupo intermediário. Veja-se ilustração no seguinte trecho de entrevista: 
(3)

Eu levanto cedo, ajudo a minha filha que fica cuidando da propriedade [...] levanto às cinco horas, fazemo todo o trabalho: tirá leite, tratá (os animais) [...] depois vô pra cidade trabalhá. Vai fazê agora em maio oito anos que eu tô nessa rotina, trabalhando no sindicato dos trabalhadores rurais. (D.L., fem., 53 anos)

Já as atividades das mulheres aposentadas nesse grupo etário são distintas, estão na base dos índices significativos de vozeamento/desvozeamento das plosivas bilabiais por elas promovidos. Desobrigadas do trabalho profissional diário, encontram tempo para um maior envolvimento com a comunidade, o que as põe na condução de práticas ligadas à sócio-história e tradições locais e em que traços do contato do português com a fala dialetal alemã emergem, se não mesmo o uso do próprio Hunsrückisch. As informantes I.B., 66 anos e I.L., 60 anos, são exemplos de líderes da comunidade. São aposentadas como professora e agricultora, respectivamente. Elas organizam grupos de atividades comunitárias que são, por sua vez, a forma de lazer local. Por exemplo, coordenam o coral (encontros semanais), jogo de bolão (esporadicamente), ginástica (uma vez por semana), teatro (apresentação de natal), grupo de $3^{\mathrm{a}}$ idade (mensal), apostolado da oração (contato mensal), vôlei (semanal), clube de mães (reunião mensal), da escola e igreja (contínuo). Veja-se trecho da entrevista de uma delas:

O meu envolvimento com a comunidade foi intenso e ainda é bastante intenso. [...] depois que eu me aposentei aqui como diretora (da escola), encaminhei a aposentadoria depois de dez anos de direção [...] eu moro com meu pai e continuo com uma vida bastante ativa aqui na comunidade, né, sô secretária da sociedade Santa Cecília que é a sociedade de cantores, envolve mais ou menos trinta membros, trinta cantores, trinta e cinco, né, [...] eu sou secretária do clube de mães que exige bastante também, a gente se envolve bastante, também sou vice-tesoureira da sociedade de água potável da comunidade [...] além assim, né, de atividades sociais, né, [...] nessa parte cultural sempre tem alguma coisa pra gente se envolvê [...] participo do grupo vida saudável (grupo de ginástica), do qual sou vice-coordenadora. (I.B., fem., 66 anos)

Entendemos que a presença de marcas de contato na fala de I.B. e do grupo de mulheres que ela representa seja efeito do papel social por elas desempenhado. São líderes culturais, atuam como zeladoras de tradições, guardiães da memória coletiva relacionada ao processo de imigração alemã ao Brasil e sua fixação nos territórios do Sul. A considerar seu grau 
de instrução, elevado para o grupo etário, e o fato de ter sido professora, ministrante de aulas de geografia, se poderia esperar que, mesmo bilíngue, minimizasse as marcas do contato com a fala dialetal no português. I.L. é, dentre as mulheres, a que apresenta a maior proporção de vozeamento/desvozeamento variável. Também é aquela que, nas práticas do canto coral, por exemplo, pode cumprimentar os outros integrantes em Hunsrückisch, mesmo que respondam em português.

O clube de mães, o que que nóis fizemo, né, por exemplo, ajudemo a comunidade, cada fim do ano a tiretoria intrega e compra algumas coisas pra comunidade, ela vê o que que falta, ou pra icreja e participa também da parte litúrgica da missa, assim, as leitura, né. Porque tem cada domingo (missa), é o clube de mães, a tiretoria escolhe o clube de mães ou a turma da catequese ou a comunidade ou a apostolado [...] isso que participemo, assim. [...] a gente ensaia toda semana (no coral), o ano inteiro, toda semana, [...] nóis ensaiemo cantos pra paile, festa e fúnebres que é o objetivo do nosso coral, né, então, a gente tem compromisso e canta no natal, enterro dos associados e casamento se eles querem, é natal, kerp, páscoa. [...] eu não sei se já perdi um (baile) nóis sempre trapalhemo (na organização do baile), né. (I.L., fem., 60 anos)

Em termos linguísticos, pode-se pensar que o português com traços do falar dialetal seja, em alguma medida, uma prática estilística, uma manifestação de identidade local que legitima o desempenho do papel de líder nas comunidades de prática. Se confirmada, num futuro relativamente próximo, a tendência desenhada pelos grupos etários mais jovens, de desaparecimento do traço de contato investigado, talvez o desempenho do papel de líder cultural em Glória prescinda desse e de outros traços, a depender de transformações na própria comunidade, principalmente econômicas e educacionais.

Portanto, o papel condicionador do sexo/gênero feminino verificado na análise quantitativa do vozeamento/desvozeamento das plosivas bilabiais no português falado em Glória não vai contra a máxima variacionista de que as mulheres liderariam processos de variação e mudança linguística adotando as variantes prestigiadas. $\mathrm{O}$ fato de um traço estigmatizado do contato do português com a fala dialetal alemã emergir na fala de mulheres deve ser compreendido localmente como manifestação cultural, como prática social feminina relacionada às demais práticas de mulheres de idade mais avançada e aposentadas, que legitimam e atribuem valor às alternantes, hoje já residuais nessa comunidade. 


\subsubsection{Battisti e Dornelles Filho (2015)}

A análise quantitativa de 7944 dados de fala de Flores da Cunha, 4710 levantados de entrevistas do VARSUL (1990) e 3234 de entrevistas do BDSer (2008-2009), mostrou que a tendência a palatalizar aumentou na comunidade nos últimos vinte anos. É o que indicam os valores de input (numa escala e 0 a 1) para os dados do VARSUL, de 0,37 e para os dados do BDSer, de 0,53. A proporção total de aplicação da regra em cada amostra conforma-se à tendência expressa pelos valores de Input: foi de $41,7 \%$ nos dados do VARSUL e de $51,7 \%$ nos dados do BDSer, como se vê na Figura 5.

Figura 5: Proporção total de aplicação da regra nos dados do VARSUL e do BDSer.

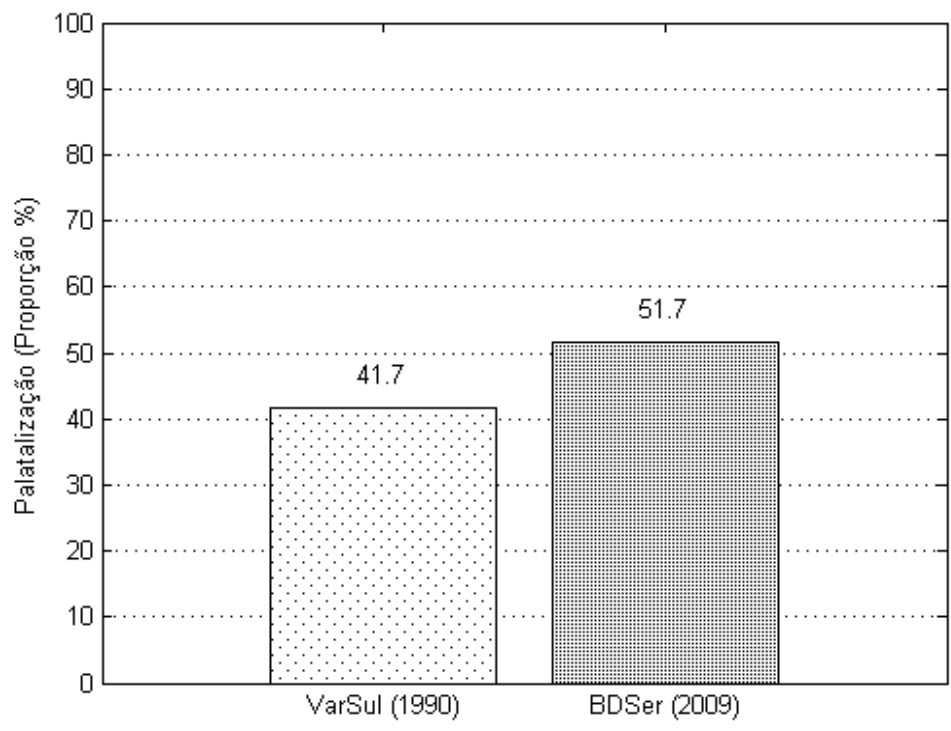

Chama atenção, na ordem de seleção dos fatores apontados como mais significativos pelo programa de análise estatística, uma mudança no posicionamento da variável sexo/gênero: foi a primeira colocada na análise da amostra do VARSUL, passou a segunda colocada na análise da amostra, como se vê no Quadro 1. 
Quadro 1: Variáveis selecionadas na análise quantitativa

das amostras do BDSer e do VARSUL.

\begin{tabular}{|c|c|}
\hline VARSUL (1990) & BDSer (2008-2009) \\
\hline Sexo/gênero & Idade \\
$\begin{array}{c}\text { Contexto fonológico seguinte } \\
\text { Qualidade da consoante-alvo } \\
\text { Idade }\end{array}$ & $\begin{array}{c}\text { Qualidade da consonero } \\
\text { Contexto fonológico seguinte }\end{array}$ \\
\hline
\end{tabular}

Entre os grupos de fatores selecionados estão variáveis linguísticas e sociais, mostrando o relevo das restrições gramaticais no condicionamento da palatalização. Nossa discussão, pela temática deste trabalho, retomará apenas os resultados das variáveis sociais.

O controle da variável idade nas duas amostras confirma que a palatalização de /t/ e /d/ é mudança em progresso em Flores da Cunha: os pesos relativos dos grupos etários mais jovens são maiores do que os pesos dos grupos mais velhos. Chama atenção o fato de o grupo etário mais jovem ter despontado na amostra mais recente, do BDSer.

Figura 6: Resultados em pesos relativos para a variável Idade nas amostras do VARSUL e do BDSer.

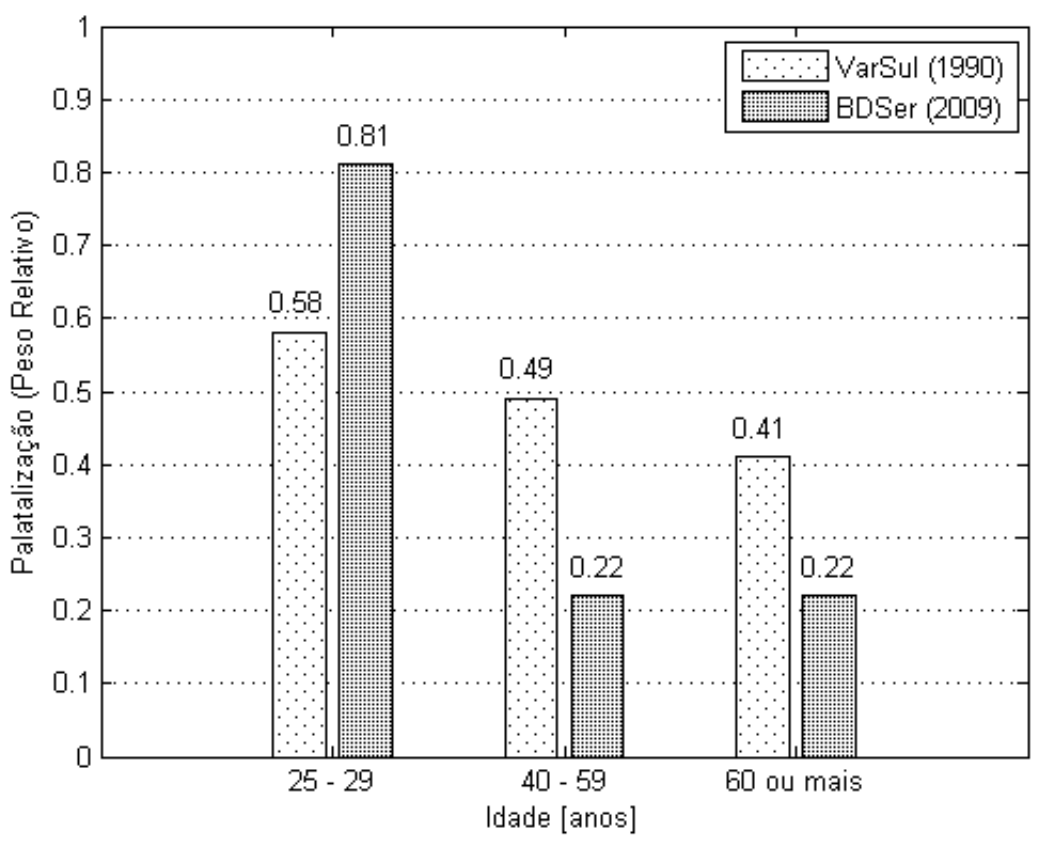


Diferentemente dos outros grupos etários, os jovens de Flores da Cunha têm hoje mais mobilidade territorial: deslocam-se a centros urbanos maiores para estudar, trabalhar e, eventualmente, em seus momentos de lazer, e retornam a Flores da Cunha, onde seguem residindo, mesmo que não seja na zona rural (na 'colônia', no vocabulário local). Nisso, aumentam as oportunidades de interação com pares de outras comunidades, tornando sua fala suscetível a inovações como a palatalização. Veja-se um trecho de entrevista sociolinguística de informante jovem do BDSer:

(6)

A gurizada daqui não quer mais trabalhar na colônia. [...] Vão pra Caxias estudar. Todos fazem faculdade, a grande maioria. Aí, então, ninguém mais quer trabalhar na colônia como acontecia antigamente, as famílias eram numerosas, as pessoas ficavam na colônia e não estudavam, né. [...] Eu acho que mais pessoas continuam morando aqui e vão e voltam, do que se mudam. São poucos que se mudam. (Inf. FC-211, 25-29 anos, fem., ZR)

Em relação à variável sexo/gênero, os pesos relativos obtidos na análise das duas amostras mostram que o fator feminino tem o mesmo papel, condiciona a palatalização em Flores da Cunha. No entanto, os efeitos da oposição feminino-masculino desacentuaram-se nos últimos vinte anos, como mostra a Figura 7.

Figura 7: Resultados em pesos relativos para a variável Sexo/Gênero nas amostras do VARSUL e do BDSer.

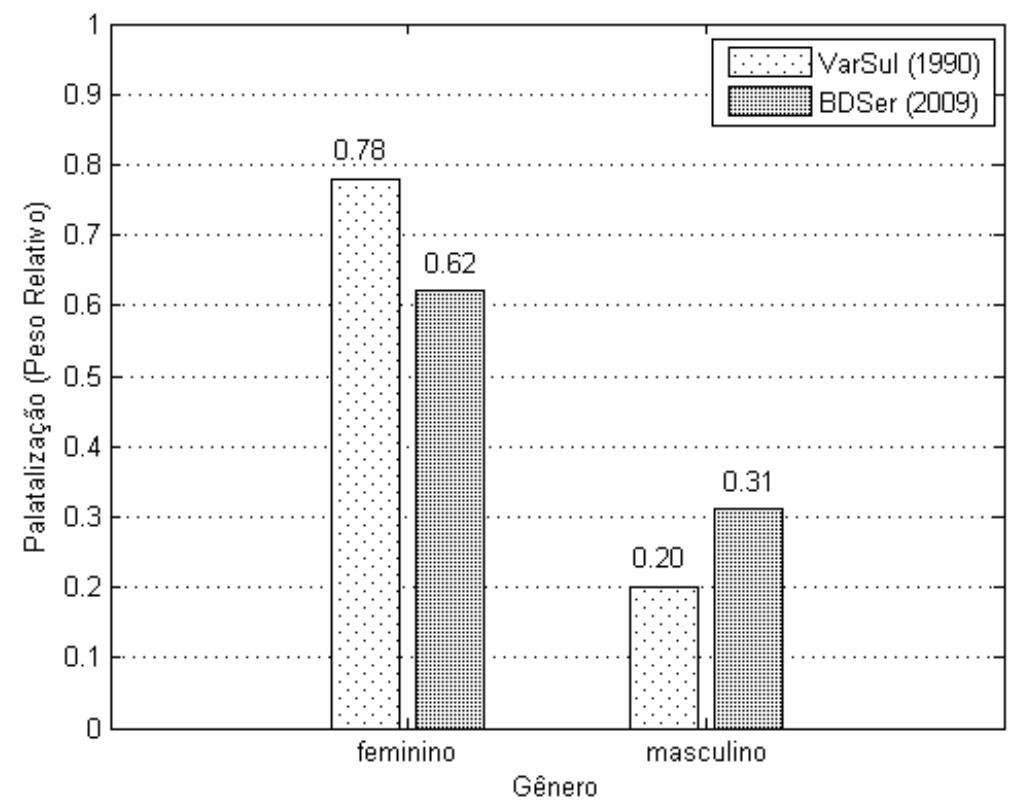


Diferenças nas práticas sociais femininas relacionadas principalmente à educação, lazer e atividades profissionais podem explicar o caráter favorecedor: as ocupações femininas (professoras, secretárias, atendentes) exigem mais uso da linguagem do que nos trabalhos domésticos. As práticas sociais das mulheres podem ser menos localizadas que a dos homens no âmbito do estudo, compras, amizades, o que, como afirmado sobre os jovens, as coloca em contato com integrantes de outras comunidades de fala. Efeito dessas interações pode ser o incremento de inovações linguísticas como a palatalização. Mas e o que dizer dos homens? Não só o aumento do peso relativo, como o incremento nas proporções de aplicação são significativos: houve aumento de $17 \%$ para $40 \%$ de palatalização pelo fator masculino da amostra do VARSUL para a do BDSer, e diminuição de $65 \%$ para $59 \%$ de palatalização pelo fator feminino. Por que a proporção da aplicação da regra do sexo/gênero feminino diminuiu e a do masculino aumentou? Que mudanças na comunidade justificariam alterações nas tendências de sexo/gênero?

Battisti e Dornelles Filho (2015) exploram pressupostos labovianos numa análise estatística complementar, para buscar resposta a essas questões. A mudança nos índices se justificaria não apenas por mudanças sócio-históricas e culturais na comunidade de fala, mas principalmente pelo percurso natural do processo de aquisição da linguagem.

De acordo com Labov (1994, p.83) e o pressuposto da mudança geracional (generational change, em inglês), nosso sistema fonológico está definido na juventude e se estabiliza na vida adulta. Mudanças linguísticas resultam de mudanças na comunidade. Já pelo pressuposto da assimetria na transmissão linguística (asymmetry of language transmission, em inglês) de Labov (2010, p.198), homens da geração mais velha (geração 1) não se envolvem na mudança, homens entre 30 e 50 anos (geração 2) são os primeiros a terem mães afetadas pelos processos e mostram um incremento rápido nos valores de aplicação equivalentes aos de suas mães (entre $50 \mathrm{e}$ 70 anos de idade). Assim, homens estarão cerca de uma geração atrás de suas mães até o fim do processo, quando a diferença de sexo/gênero diminui. É o que pode explicar a aproximação nos índices dos fatores feminino e masculino no intervalo de vinte anos.

Os autores consultaram as fichas sociais dos vinte e quatro informantes que forneceram dados para a análise (quantitativa) em tempo real, buscando a idade declarada pelo informante no momento da entrevista. Seguindo o pressuposto da mudança geracional, tomou-se a idade de quinze anos como aquela em que o sistema fonológico se estabilizaria e calculou-se o ano em que cada informante tinha quinze anos. O cruzamento dessa informação com as proporções individuais de palatalização e o sexo/gênero dos 

informantes pode ser visto na Figura 8.

Figura 8: Cruzamento da idade de estabilização do sistema fonológico, proporção individual de palatalização e sexo/gênero dos informantes.

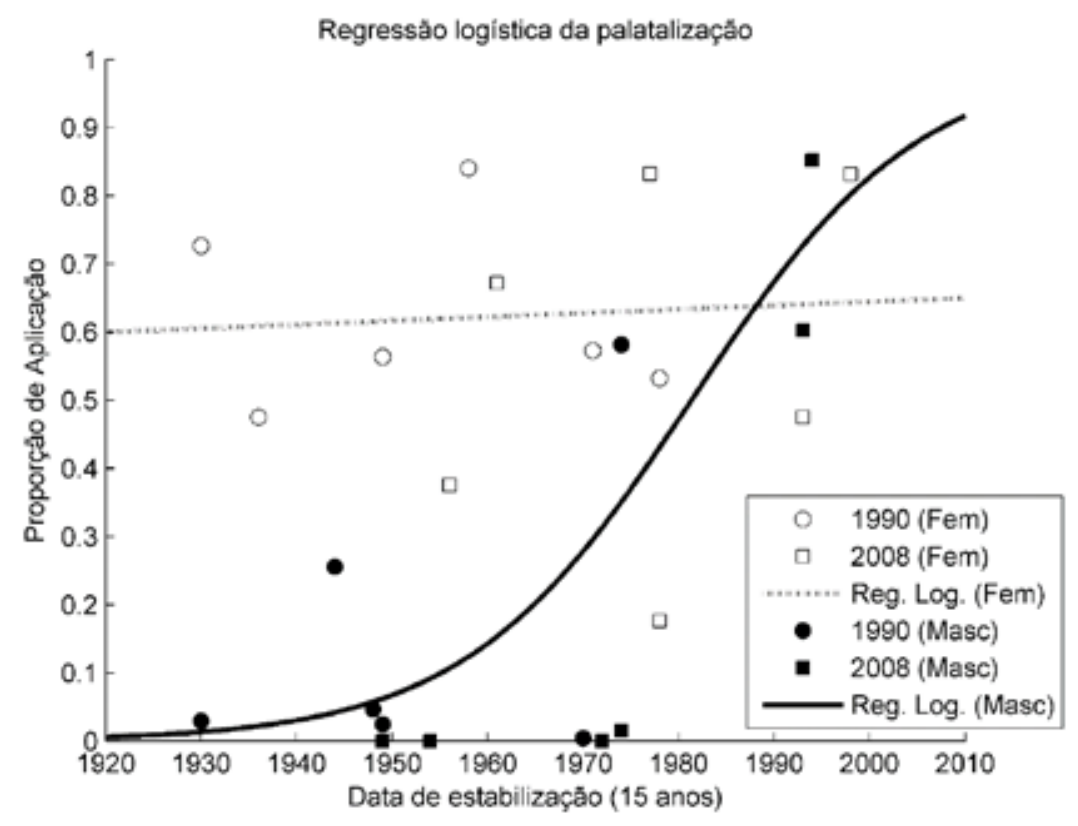

No gráfico da figura 8, a linha de regressão cinza mostra que a aplicação da regra pelo fator feminino é mais alta do que a aplicação pelo fator masculino, mas se mantém praticamente estabilizada em quase cem anos. E, há cem anos, já havia palatalização na fala de mulheres quando o processo era inexistente na fala dos homens. É o que mostra a linha de regressão preta, além do rápido aumento da palatalização pelo fator masculino nos últimos anos. Se houve progressão da regra por sexo/gênero, ela ocorreu na fala masculina, como parte do padrão previsto pelo pressuposto da assimetria na transmissão linguística.

Além da assimetria, vale registrar as mudanças havidas na comunidade que se podem associar a esse padrão de sexo/gênero. As atividades profissionais dos homens diversificaram-se nos últimos anos, principalmente com a revitalização do setor industrial no ramo moveleiro e o incremento da indústria da uva e do vinho, na produção de sucos e vinhos. São atividades que oportunizam aos homens a realização de práticas comerciais no Brasil e exterior e o contato com integrantes de outras comunidades de fala. A adoção de um padrão suprarregional com palatalização pode ser prática linguística com contornos estilísticos, motivada pelas demandas profissionais. 
No que diz respeito à comunidade de fala em si, vale registrar que Flores da Cunha, como as demais localidades da antiga região colonial italiana do Rio Grande do Sul (RCI-RS), abre-se a inovações, inclusive às linguísticas (palatalização), mas valoriza aspectos da cultura local, de base étnica italiana. Há hibridismo cultural na RCI-RS: práticas tradicionais e inovadoras coexistem. A mudança linguística (entre outras mudanças) progride, mas moderadamente.

\section{CONSIDERAC̣ÕES FINAIS}

Os estudos retomados e discutidos neste trabalho referem-se à aplicação de processos variáveis no português falado em comunidades do sul do Brasil onde houve e ainda há contato com línguas de imigração. Interpretar os efeitos de sexo/gênero implica compreendê-los na interação dessa variável com outras variáveis sociais e também com referência a elementos sócio-históricos e culturais das comunidades de fala investigadas.

No estudo do vozeamento/desvozeamento variável das plosivas bilabiais no português falado em Glória, o fato de o sexo/gênero feminino e o grupo etário mais idoso tenderem a promover um processo que gera formas estigmatizadas e já em desaparecimento relaciona-se a práticas sociais locais que envolvem bilinguismo português-dialeto alemão e resgatam tradições dos imigrantes, como as do canto coral, clube de mães, festas religiosas, apostolado da oração e atividades comunitárias. Essas mulheres atuam como gestoras nativas do patrimônio cultural da comunidade, o que legitima e valoriza as formas estigmatizadas. Por isso, não se pode afirmar que os resultados de Glória para o fator feminino contradigam a máxima laboviana de que as mulheres são líderes da variação e mudança pela adoção de formas prestigiadas. Além de o processo tender ao desaparecimento, as formas vozeadas/desvozeadas adquirem algum valor nas comunidades de prática locais em razão dos papéis desempenhados pelas mulheres idosas de Glória, as promotoras do processo, nesses grupos.

Em Flores da Cunha, a constatação de que o comportamento que de fato mudou foi o de homens na aplicação do processo de palatalização de /t/ e /d/ é melhor compreendido em relação aos padrões culturais locais. $\mathrm{Na}$ comunidade, reproduzem-se padrões tradicionais (relacionados à história da imigração italiana) em diferentes campos - gastronomia, religião, família, ocupações, lazer -, mas com algumas inovações. Os jovens, que tendem a palatalizar e fazem o processo progredir na comunidade, estudam e relacionam-se com pares em comunidades vizinhas, mas retornam a Flores da Cunha e seguem vivendo lá, indicando uma orientação positiva à comunidade. $\mathrm{O}$ mesmo se pode dizer de homens e mulheres. As mulheres 
palatalizam mais do que os homens, mas o comportamento desses últimos vem fazendo um percurso que anuncia a futura aproximação nos índices dos fatores masculino e feminino. É o que revelou a análise estatística mais refinada, guiada por pressupostos labovianos, esclarecendo os efeitos de sexo/gênero como implicados pelo processo de aquisição e relacionados a mudanças na comunidade.

Os estudos revisados vão além do tratamento quantitativo de dados de variação, lançando mão de procedimentos metodológicos qualitativos na consideração a práticas sociais e elementos da sócio-história local para compreender os efeitos de sexo/gênero nos processos investigados. A investigação de atitudes linguísticas dos membros das comunidades de fala para com o português e as línguas de imigração poderia esclarecer os valores atribuídos a diferentes traços do contato e a própria prática bilíngue. Essa etapa não realizada é a perspectiva de nossos estudos futuros, que trarão também mais esclarecimentos sobre os efeitos de sexo/gênero na variação linguística.

\section{REFERÊNCIAS}

ALTENHOFEN, Cléo Vilson; MARGOTTI, Felício Wessling. O português de contato e o contato com as línguas de imigração no Brasil. In: MELLO, Heliana; ALTENHOFEN, Cléo Vilson; RASO, Tommaso. (Orgs.). Os contatos linguísticos no Brasil. Belo Horizonte: Editora UFMG, 2011. p. 289-315,

BATTISTI, Elisa. Palatalização de T e D. In.: BISOL, Leda; BATTISTI, Elisa. (Orgs.). O português falado no Rio Grande do Sul. 2014.p.105-120.

BATTISTI, Elisa; DORNELLES FILHO, Adalberto Ayjara. Análise em tempo real da palatalização de /t/ e /d/ no português falado em uma comunidade ítalo-brasileira. Revista da ABRALIN, v.14, n.1, p. 221-246, 2015.

BATTISTI, E.; ROSA, R. S. Da. Variação e mudança linguística: análise em tempo real da palatalização das oclusivas alveolares em um falar do Rio Grande do Sul. Web-Revista SOCIODIALETO, v.2, n.2, 2012.

BLAKE, Renée; JOSEY, Meredith. The /ay/ diphthong in a Martha's Vineyard community: what can we say 40 years after Labov? Language in Society, n. 32, v. 4, p. 451-485, 2003.

ECKERT, Penelope. Linguistic variation as social practice. Oxford, Blackwell, 2000.

KAMIANECKY, Fernanda. A palatalização das oclusivas dentais /t/ e /d/ nas comunidades de Porto Alegre e Florianópolis: uma análise quantitativa. 2002. 114 f. Dissertação (Mestrado em Linguística Aplicada), Faculdade de Letras, Pontifícia Universidade Católica do Rio Grande do Sul, Porto Alegre: PUCRS, 2002. 
LABOV, William. Padrões sociolinguísticos. São Paulo: Parábola, 2008 [1972]. Tradução de Marcos Bagno.

LABOV, William. Principles of linguistic change: cognitive and cultural factors. Malden/Oxford/West Sussex: Wiley-Blackwell, 2010.

LABOV, William. Principles of linguistic change: internal factors. Oxford/Cambridge: Blackwell, 1994.

LABOV, William. Principles of linguistic change: social factors. Oxford/Malden, Blackwell, 2001.

LABOV, William. Sociolinguistic patterns. Philadelphia: University of Philadelphia Press, 1972.

LARA, Claudia Camila. Variação fonológica, redes e práticas sociais numa comunidade bilíngue português-alemão do Brasil meridional. 2013. 105 f. Dissertação (Mestrado em Letras) - Programa de Pós-Graduação em Letras, Universidade Federal do Rio Grande do Sul, Porto Alegre, 2013.

MILROY, Lesley. Language and Social Networks. 2.ed. Oxford, Blackwell, 1987. MILROY, Lesley. Social Networks. In: CHAMBERS, J. K.; TRUDGILL, Peter; SCHILLING-ESTES, Natalie. Eds. The handbook of language variation and change. Oxford Blackwell Publishing, 2002.

NOLL, Volker. O português brasileiro: formação e contrastes. São Paulo: Globo, 2008. 
150 